\title{
Comunidade Ampliada de Pesquisa (CAP) como dispositivo de cogestão: uma aposta no plano coletivo
}

Maria Elizabeth Mori ${ }^{1}$

Fábio Hebert da Silva² Fernanda Luz Beck ${ }^{3}$

A Política Nacional de Humanização (PNH) foi criada em 2003, pelo Ministério da Saúde (MS), com o objetivo de encontrar "outras respostas à crise da saúde, identificada por muitos como falência do modelo SUS" (Benevides, Passos, 2005, p.389). Usuários e trabalhadores da Saúde reivindicavam o direito à saúde por meio do acolhimento resolutivo e melhores condições de trabalho, respectivamente. As propostas humanizadoras ${ }^{4}$ não questionavam os modelos de atenção e de gestão instituídos, mas expressavam-se em ações fragmentadas, numa imprecisão e fragilidade do conceito de humanização. O termo humanização ligava-se ao "voluntarismo, ao assistencialismo, ao paternalismo ou mesmo ao tecnicismo de um gerenciamento sustentado na racionalidade administrativa e na qualidade total" (Benevides, Passos, 2005, p.390).

A PNH, portanto, vem para responder ao desafio da criação de uma política transversal - e não mais programas desarticulados - "com princípios, métodos e diretrizes como instrumentos de ação com um efeito de positivação do SUS" (Pasche, 2008) $)^{5}$, apostando nas experiências concretas do "SUS que dá certo".

Estes princípios tratam da indissociabilidade entre os modelos de gestão e da atenção; transversalidade como ampliação do grau de comunicação existente entre os diferentes programas e políticas, saberes profissionais e instâncias do SUS (Ministério da Saúde e Secretarias Estaduais e Municipais) e dos serviços da rede (Atenção Básica e Secundária e Terciária); autonomia e protagonismo dos sujeitos envolvidos na produção de saúde, a corresponsabilização, o estabelecimento de vínculos solidários, a construção de redes de cooperação e a participação coletiva no processo de gestão (Brasil, 2008a).

A PNH, portanto, não pode ser confundida com uma ação pontual, mas uma política de governo que se pretende pública ao apostar na criação de condições para a efetivação de novos modos de organização da gestão e do cuidado nas unidades e serviços do SUS, produzindo mais saúde para as pessoas e com o envolvimento de mais pessoas. Neste sentido, passa a convocar gestores do nível central, trabalhadores e usuários para o desenvolvimento de uma produção de cuidado em saúde, cuja ênfase está na dinâmica das relações, no encontro e nas trocas entre diferentes sujeitos e coletivos. O respeito às singularidades e o reconhecimento da alteridade são pilares dessas relações.

Para Sadala (1999), a alteridade deve ser entendida como um critério fundamental da ética aplicada às situações da saúde, uma vez que trabalhador e
${ }^{1}$ Ministério da Saúde, Secretaria de Atenção à Saúde, Política Nacional de Humanização (MS/ SAS/PNH). SHIN QL 01, conjunto 02 , casa 15 , Lago Norte. Brasília, DF, Brasil. 71505-025.

beth.mori@gmail.com ${ }^{2,3}$ MS, SAS, PNH.

\footnotetext{
${ }^{4} \mathrm{Na}$ busca da qualidade na atenção ao usuário, a partir de 1999 o MS propôs algumas ações e programas, entre outros: Programa Nacional de Humanização e Atenção Hospitalar (PNHAH), Programa Nacional de Avaliação dos Serviços Hospitalares (PNASH), Programa de Modernização Gerencial dos Grandes Estabelecimentos de Saúde.

${ }^{5}$ Dario Pasche, coordenador nacional da $\mathrm{PNH}$, abordou este tema na roda de discussão do Eixo I: "Princípios do SUS e a humanização das práticas de saúde", no Seminário "A humanização do SUS em debate", proposto pela $\mathrm{PNH}$ realizado em Vila Velha, ES, dias 24 e 25 de junho de 2008, com o objetivo de ampliar a interlocução dos formuladores da PNH com a comunidade acadêmica.
} 
usuário, cada qual numa posição e função, devem ser capazes de apreender o outro na plenitude de sua dignidade, de seus direitos e, sobretudo, da sua diferença.

Deslandes (2008) ${ }^{6}$ aborda uma questão central relacionada com a criação de espaços de análise coletiva do trabalho (gestão e atenção): o cuidado, o zelo e a responsabilização. A ética como cuidado de si e do outro se revela como um ponto complexo dentro do tema das dinâmicas comunicacionais. "O manejo das narrativas, da escuta, a conversa e o diálogo são tecnologias das mais imprescindíveis para a produção do cuidado humanizado em saúde" (Deslandes, 2008, p.1). Por isso, a aposta na humanização como um paradigma "ético, estético e político" para transformar as relações de trabalho e de cuidado com o 'outro legítimo' para a real produção de saúde.

\begin{abstract}
Ética porque implica a atitude de usuários, gestores e trabalhadores de saúde comprometidos e co-responsáveis. Estética porque acarreta um processo criativo e sensível de produção de saúde e de subjetividades autônomas e protagonistas. Política porque se refere à organização social e institucional das práticas de atenção e gestão na rede do SUS. (Brasil, 2008a, p.62)
\end{abstract}

Os meios pelos quais o modelo político da PNH tem se atualizado em agenciamentos coletivos concretos estão direcionados, em grande parte, para um pacto de cogestão e de "outra" valorização do trabalho. Para se efetivar esta proposta ética e política visando modelos de atenção e de gestão mais próximos da vida cotidiana daqueles que compõem o SUS, lança-se mão de dispositivos que ultrapassam simples normatizações (sem negar sua importância dentro dos processos de trabalho) e criam-se modos outros de organização do trabalho com base nas experiências singulares de cada lugar. Dentre estes dispositivos, encontrase a Comunidade Ampliada de Pesquisa (CAP), um método de análise dos processos de trabalho que passa por um exercício cotidiano de produção de conhecimento, contribuindo para a transformação da realidade instituída.

O presente texto situa a CAP como aposta em uma metodologia de construção coletiva que tem, como perspectiva ética, a sustentação autônoma do conjunto de trabalhadores da Saúde. Objetiva-se refletir sobre a construção de espaços de diálogo onde os trabalhadores possam analisar os efeitos dos processos de trabalho em sua própria saúde.

\section{A roda de conversa como possibilidade de encontro dialógico entre sujeitos no campo do trabalho contemporâneo}

Gastão Campos (1991) afirma que o conceito de humanização fala diretamente sobre os seres humanos, e que um dos grandes problemas da lógica de mercado contemporânea é o esquecimento das pessoas. Políticas econômicas têm sido avaliadas de acordo com sua capacidade de produzir crescimento ou estabilidade monetária, e não necessariamente de melhorar as condições de vida. A ordenação do espaço urbano há muito deixou de lado a preocupação com o bem-estar coletivo. Em saúde, é comum a redução de pessoas a objetos a serem manipulados pela clínica ou pela saúde pública. Pela perspectiva da $\mathrm{PNH}$, o humano diz respeito ao protagonismo dos sujeitos e à centralidade da vida humana.

Segundo o psicanalista Joel Birman (2006), a partir dos anos noventa, são cada vez mais frequentes, na clínica, usuários apáticos e desesperançados que reclamam da indolência e sofrem de mal-estares difusos. O vazio se manifesta em

\author{
${ }^{6}$ Roda de discussão do \\ Eixo II: "Humanização e \\ organização dos serviços \\ e práticas de saúde", no \\ Seminário referido na \\ nota anterior.
}


reclamações vagas e aflitas nas quais o sujeito se sente engolfado e impotente, tais como as depressões, a chamada síndrome do pânico e as compulsões em geral. Na compulsão, denota-se um sujeito que, para livrar-se do mal-estar, utiliza-se de ilusões de breves e fortuitos momentos de prazer, estimulado pelo "mundo externo", tenta preencher-se com drogas ilícitas e lícitas, alimentos, sexo, bens materiais etc. Dessa forma, surgem modos contemporâneos de sofrimento. A depressão, condição radical do desalento, surge quando o sujeito perdeu qualquer possibilidade de construir um projeto de vida.

Algumas outras características desse sofrimento são: o gosto pelo efêmero; o presente como instante fugaz; a perda de referência temporal; a obsolescência das qualificações para o trabalho, dos valores e das normas de vida; o prestígio do paradigma da moda; a competição como forma de constituição da identidade pessoal; o medo gerado pela insegurança; a perda de autonomia sob o poderio do 'discurso competente'; o consumo; a supervalorização midiática da juventude, da beleza, da saúde ideal, do sucesso, do poder etc. A busca pela "felicidade" própria, identificada pelo sucesso como atributo unicamente pessoal, é atualizada pela eliminação do outro, do diferente (eliminação não necessariamente física, mas moral, profissional etc.).

As situações de trabalho em saúde se desenrolam em um cenário onde as condições dos processos de trabalho têm impactado negativamente a vida do trabalhador (Santos-Filho, 2007): precarização do trabalho e de suas condições (vínculos diversificados propiciam salários diferenciados e redução de direitos até para as mesmas categorias, infraestrutura deficiente); organização e relações de trabalho calcadas na lógica de mercado e em modelos de gestão tradicionais, que dificultam a compreensão e a implementação efetiva da gestão participativa e cogestão (burocracia excessiva, limitação da autonomia, da corresponsabilização e do protagonismo dos trabalhadores); subvalorização do servidor público pela população e governo, gerando privatizações, instabilidades e adversidades de diferentes ordens; situações de violência no âmbito do cotidiano dos serviços (entre trabalhadores e usuários e trabalhadores); concepção de "rede" que avança na perspectiva da "regulação" dos serviços, mas não apresenta proposta que propicie a participação ativa e criativa de todos os atores, saberes e instituições que compõem o sistema.

Essas situações têm requerido habilidades e atitudes de improvisação por parte dos trabalhadores, "criação" e "invenção" nos modos de enfrentar o trabalho extenuante. Por isso temos afirmado que "nos processos de trabalho em saúde as instituições devem ser espaços de produção de bens e serviços para os usuários e, também, espaços de valorização do potencial inventivo dos sujeitos que nelas trabalham" (Brasil, 2008b, p.4).

\begin{abstract}
Não é possível propor/pensar a gestão em saúde, seja a gestão do Sistema, seja a dos serviços, seja a gestão da atividade, sem que se leve em conta o modo como estas políticas se constroem e o que nelas se reafirma como "público". Entendemos que a construção de políticas públicas deve estar conectada e comprometida com a coletivização da gestão, com a publicização das relações entre trabalho (saberes), sujeitos (necessidades, desejos e interesses) e poderes (modos de por em relação saberes e sujeitos). (Barros, Barros, 2007, p.65)
\end{abstract}

Diante disso, uma política pública de saúde tem a função de engendrar relações mais amplas de trabalho, a fim de promover diálogos nos dissensos. Diálogos cada vez mais efetivos na construção coletiva de um SUS sustentado por sua dimensão pública, que servirão também de orientação para o trabalho em saúde, tanto na gestão quanto no cuidado, por princípio, indissociáveis.

O diálogo produzido em rodas de conversas é a estratégia mais importante para a cogestão dos processos de trabalho no SUS. Segundo Campos (2003), o objetivo dessas rodas é a construção de projetos de intervenção para abrir possibilidades, superar os impasses institucionais e incluir as relações de poder, afeto e a circulação de conhecimentos em análise.

Então, quando se trata da criação de espaços dialógicos, pretendemos pensar coletivamente modos de viver o que chamamos de indissociabilidade entre gestão/atenção e transversalidade na experiência concreta. E, para isso, é necessário considerar as "tecnologias de manejo de escuta e de negociação de regras", e inventar "modos de lidar (relacionar-se) com a variabilidade das situações de trabalho" (Deslandes, 2008, p.1). 


\section{CAP e cogestão}

Na história do mundo do trabalho, encontramos experiências de luta por ambientes laborais mais saudáveis. Na década de 1970, no bojo da efervescência dos movimentos pelos direitos humanos, surge o "Modelo Operário Italiano de Luta pela Saúde" (MOI). Paralelamente ao crescimento socioeconômico e aumento da produção nas indústrias, ocorria uma desqualificação e desgaste do trabalhador, com baixos salários e péssimas condições de trabalho. Para enfrentar esta situação, ocorreu uma mobilização coletiva formada por "técnicos" da área da saúde, operários e sindicalistas, que se debruçaram sobre a análise da organização e dos processos de trabalho (Brasil, 2009).

Este novo modelo de produção de conhecimento - relação entre saberes "formais" dos pesquisadores (acadêmicos/científicos) e saberes "informais" dos trabalhadores - aparece como uma nova forma de fazer pesquisa no ambiente de trabalho e de interpretar o processo saúde e doença. Denominado de Comunidade Científica Ampliada (CCA), ao invés de ignorar ou desqualificar a experiência dos trabalhadores, o saber científico dialoga com o saber operário, tendo, como ponto de partida, a pesquisa sobre o local de trabalho. Buscava-se compreender as condições e as dinâmicas que podem gerar o sofrimento e conduzir ao adoecimento, bem como as estratégias que esses trabalhadores criam no seu dia-a-dia de afirmação de saúde e de vida.

No Brasil, influenciados pela experiência italiana, um grupo de pesquisadores inicia um projeto de pesquisas sobre a problemática da saúde dos/as trabalhadores/as em uma área diferente da nossa, nas escolas públicas. Esse projeto tinha por objetivo compreender a relação entre o trabalho e os processos de saúde-doença, numa perspectiva de transformar as situações consideradas nocivas. Assumindo e afirmando que o trabalho é elemento central na produção do processo saúde-doença e, consequentemente, que a transformação do trabalho é fundamental para a conquista da saúde. (Brasil, 2009)

Inspirados na expressão Comunidade Científica Ampliada, estes pesquisadores preferiram denominar o espaço no qual poderia se constituir essa rede de informações, a troca de experiências e construção de outras estratégias coletivas, por outra expressão: Comunidade Ampliada de Pesquisa (CAP).

Nos aspectos relativos à diretriz "Valorização do trabalho e do trabalhador de saúde" na PNH, a CAP tem sido um dispositivo de intervenção para uma compreensão ampliada das relações existentes entre saúde e trabalho, considerados indissociáveis. Entendemos que é impossível cuidar da saúde sem considerar as formas de organização adotadas pelos trabalhadores para lidar com as demandas do cotidiano de trabalho e as estratégias de enfrentamento das experiências de sofrimento em serviço.

Promover saúde nos locais de trabalho é aprimorar a capacidade de compreender e analisar o trabalho de forma a fazer circular a palavra, criando espaços para debates coletivos. A gestão coletiva das situações de trabalho é critério fundamental para a promoção de saúde. Trata-se de compreender as situações nas quais os sujeitos trabalhadores afirmam sua capacidade de intervenção no processo de tomada de decisões no âmbito das organizações de saúde. (Brasil, 2008b, p.8)

Dentro dessa perspectiva de criar espaços dialógicos nos serviços, a CAP, inserida no Programa de Formação em Saúde e Trabalho (PFST) ${ }^{7}$, composta por multiplicadores (consultores e apoiadores da PNH, pesquisadores e trabalhadores locais das unidades de saúde), implica a transformação das condições adversas de trabalho. 


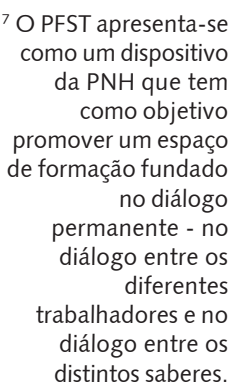

Deseja-se que o encontro e o diálogo crítico entre os diferentes saberes e práticas subsidiem e orientem o trabalho em equipes multiprofissionais atentas à análise da relação dinâmica entre o fazer e o pensar sobre o cotidiano do trabalho e a produção de saúde. A intervenção coletiva, ao tornar o trabalho mais criativo e menos repetitivo, promove a saúde do trabalhador e contribui para a transformação social.

A metodologia de implantação do PFST pode ser adaptada à realidade dos locais de trabalho. Inicialmente, os participantes/trabalhadores de saúde organizam módulos de leitura e discussão de textos sobre saúde, trabalho, gestão e grupalidade. As discussões destes textos remetem os trabalhadores ao próprio ambiente de trabalhos e às condições de saúde e de sofrimento, reafirmando a inseparabilidade entre saúde e trabalho.

E nessa direção temos experimentado o PFST, cujo maior desafio tem sido o de conjugar diferentes pesquisas, por em diálogo crítico os conhecimentos e análises científicas com ações práticas concretas de mudanças, como se espera da área da saúde pública. (Santos-Filho, Barros, 2007, p.132-3)

Este processo dialógico crítico permanente propiciado pelo PFST/CAP não se limita a ser um momento de transmissão de informações, de conhecimentos, mas, antes, um momento de escuta e de abertura para o outro, no diálogo. Essa abordagem tenta enfatizar as diferentes vozes que compõem qualquer diálogo, fazendo um convite à aceitação do outro, legitimando e reconhecendo a validade do saber do outro, explicitando a riqueza das experiências de vida e estratégias inventadas.

Esses espaços que permitem o diálogo das práticas no processo de trabalho são instrumentos essencialmente cogeridos, onde o trabalhador, estabelecendo parcerias, constitui-se como ator no processo de investigação sobre a questão da saúde e sua relação com os processos de trabalho. O objetivo é que cada trabalhador torne-se também um multiplicador desse conhecimento, aumentando a rede de cooperação de informações e experiências sobre o trabalho.

A idéia neste processo de formação profissional em Saúde Pública é que cada um é sujeito ativo de um processo de investigação sobre os assuntos relacionados à saúde e ao trabalho. Cada trabalhador, ao participar desse processo, é convocado a: apropriar-se dos conceitos apresentados, realizar estudos sobre sua realidade, socializar suas produções e debatê-las nos encontros da CAP.

No processo de trabalho, os trabalhadores "usam de si" por si. A cada situação que se coloca, o trabalhador elabora estratégias que revelam a inteligência que é própria de todo trabalho humano. Portanto, o trabalhador também é gestor e produtor de saberes e novidades. Trabalhar é gerir. Gerir junto com os outros. (Brasil, 2008b, p.7)

Nesse sentido, a CAP é muito mais uma "função" do que propriamente um "lugar", pois se trata do uso que se faz dela. Então, é mais bem definida como uma "estratégia" para se disparar o exercício dos princípios da PNH. A simples implantação da CAP não garante que, nos processos de análise coletiva do trabalho disparados, haja transformação do modelo de gestão instituído. Temos nos deparado, por exemplo, com situações onde os trabalhadores utilizam o espaço para reproduzir uma forma de funcionamento paralisante, onde a reclamação e as queixas restringem qualquer possibilidade de mudança no sentido da cogestão: "Como vamos propor 
mudanças se o gestor não nos apoia? Eles nunca estão presentes", "Os trabalhadores não sabem o que é o lugar da gerência! Reclamam que não participamos dos processos, mas quando estamos presentes todos se calam!", "Nada vai dar certo se não começar a mudar de cima!", "Os trabalhadores fazem é corpo mole!" Falas como estas permeiam intensamente os grupos de discussão.

Nestes momentos de entropia é que a intervenção do apoio institucional se faz potente. Os consultores, apoiadores externos, podem provocar o deslocamento necessário para o exame desta situação. "Por estarem menos implicados do que os dirigentes e membros da equipe, com as disputas internas por poder e com a circulação viciada de afetos. Podem ajudar o grupo a enxergar e a trabalhar impasses fundados nesta dinâmica" (Campos, 2003, p.94).

A CAP é uma estratégia de compartilhamento de experiências e troca de afetos na qual a própria humanização torna-se a atualização de ações éticas, e não afirmação de identidades fixas (a visão do "especialista", do "usuário", do "gestor"). Como podemos construir coletivamente modos de fazer isso nos serviços? Essa é a questão que direciona a CAP. Os dispositivos não são "coisas" prontas que se implantam em determinados serviços sem que se coloquem em análise as formas de organização que os processos de trabalho têm produzido. "A perspectiva de valorização é algo a ser compreendida e construída com o próprio trabalhador, a partir de suas realidades de trabalho e negociações que se deve disparar no próprio cotidiano dos serviços, das equipes, da rede. Não cabem, portanto, "prescrições", nem "receitas" de valorização" (Santos-Filho, 2007, p.261).

Pensar essa questão coletivamente é a direção que esta proposta de intervenção pretende seguir, de modo que possamos incorporar, ao nosso fazer cotidiano, isso que estamos chamando de análise coletiva do trabalho. A CAP aponta para um maior diálogo dos saberes (experiência e conceito) e para um trabalho mais saudável nos serviços do SUS, além da ampliação dos momentos de aprendizagem coletiva que permitem a construção de ferramentas de análise das condições geradoras de sofrimento e adoecimento.
O trabalhador não é mera vítima que sucumbe às sistemáticas tentativas de desqualificação/ expropriação. O trabalho desempenha função importante na luta contra o adoecimento, na medida em que, sendo invenção, (re)existe, (re)criando o trabalhador e o próprio processo de trabalho. Invenção de si e de mundo, esta é a face do processo de trabalho que queremos na política de humanização afirmar, criando condições de emergência dos fazeres, dando visibilidade às práticas. Desfazer a relação dor-desprazer-trabalho passa a ser desafio a ser enfrentado com os trabalhadores. (Barros, Barros, 2007, p.67)

A potencialidade de transformação da realidade proporcionada pela CAP configura-se na ampliação da escuta e da visão do outro como alguém capaz de colaborar na compreensão da realidade. Um novo modo de perceber o cotidiano vivido, isto é, o que antes era considerado natural, simples, fácil, ganha novos sentidos. Multiplicando a experiência de investigação, de análise, de descoberta, de debate, poderá ser possível enriquecer a própria experiência. Espaços onde a cogestão ganha contornos claros, mas não endurecidos e, desta forma, temos outra valorização dos processos de trabalho.

A cogestão qualifica a gestão participativa. Cogestão é um arranjo, um modo de atuação de uma gestão participativa. $O$ "co" é a inclusão de outros sujeitos. Também indica uma abertura do conceito de gestão. Corresponsabilização de acordos, combinações e pactuações realizadas nos espaços de gestão. "Aqui está o cerne da democratização das instituições, já que isso somente ocorrerá quando houver possibilidade de que todos exerçam um pedaço da gestão" (Campos, 2003, p.94).

Tratamos, portanto, de um imperativo ético: criação de métodos de acolhimento do outro. $\mathrm{O}$ método é incluir. A inclusão não é para fazer qualquer coisa. É abrir espaço para a conversa e para a democratização das instituições, democratizar a organização do trabalho e as organizações de saúde. 0 trabalhador ainda tem pouco (muitas vezes nenhum) espaço para discutir sobre seu trabalho. Cogestão significa colocar em discussão o tema da democracia e da ética.

A corresponsabilização se efetiva com métodos de cogestão: colegiados gestor, oficinas, câmaras técnicas e rodas de conversa. Estes não são espaços de mera troca de informaçãa entre emissor e receptor, mas, sim, de inclusão de sujeitos, saberes, experiências etc. A roda pode ser o espaço para se 
Segundo Lourau (1975, p.284), um analisador é aquilo que permite revelar a estrutura da organização, provocá-la, forçá-la a falar. É o acting-out institucional. discutir a dor, a alegria, o prazer e de ofertas de tecnologia (Campos, 2000). O PFST pode ser um lugar onde nascem rodas. A CAP é uma roda.

A PNH, portanto, indica um modo de fazer cogerido para enfrentar os desafios do cotidiano na saúde, considerando os acúmulos já conquistados. Qualquer problema só pode ser resolvido de forma satisfatória se nos comprometermos em superá-lo. Reorganização dos processos de trabalho não trata do fim dos problemas, mas de outros modos de lidar com eles. Os dispositivos da PNH não são fórmulas para eliminar problemas, mas para transformá-los em desafios. Tudo pode voltar à estaca zero se não conseguimos incluir as pessoas para pensarem juntas na melhor estratégia. Cuidar da saúde é dever do estado e direito do cidadão. Para isso, é necessário construir contratos com a população e com os trabalhadores.

Os princípios do SUS - universalidade, integralidade e equidade - convocam a cogestão pela inclusão da diferença: sujeitos, saberes, movimentos sociais e analisadores ${ }^{8}$. O conceito de humanização, redefinido segundo os princípios e as diretrizes da PNH, e a adoção do dispositivo PFST/CAP levam em conta que os trabalhadores são sujeitos sociais engajados em práticas locais e que, se mobilizados, são capazes de transformar o cotidiano do trabalho, transformando-se a si próprios neste mesmo processo. Trata-se, então, de investir, com base nesta concepção de humano, na produção de outras formas de interação entre os sujeitos que constituem os sistemas de saúde, deles usufruem e neles se transformam, acolhendo tais atores e fomentando seu protagonismo (Benevides, Passos, 2005).

O SUS é um espaço de construção de compromissos, de corresponsabilidade com a constituição de uma política pública. Para isso, é necessária a superação da fragmentação dos serviços, e a solução está na capacidade de se compreender o problema e se construírem estratégias para enfrentá-lo. A CAP é uma dessas estratégias.

\section{Colaboradores}

Os autores trabalharam juntos em todas as etapas de produção do manuscrito.

\section{Referências}

BARROS, M.E.; BARROS, R.B. Da dor ao prazer no trabalho. In: SANTOS-FILHO, S.B.; BARROS, M.E.B. (Orgs.). Trabalhador da saúde: muito prazer! Protagonismo dos trabalhadores na gestão do trabalho em saúde. Ijuí: Ed. Unijuí, 2007. p.61-72.

BENEVIDES, R.; PASSOS, E. Humanização: um novo modismo. Interface - Comunic., Saúde, Educ., v.9, n.17, p.389-94, 2005.

BIRMAN, J. Arquivos do mal-estar e da resistência. Rio de Janeiro: Civilização Brasileira, 2006.

BRASIL. Ministério da Saúde. Secretaria de Atenção à Saúde. Núcleo Técnico da Política Nacional de Humanização. Caderno de Textos do Programa de Formação em Saúde e Trabalho/PFST. Brasília: Ministério da Saúde, 2009. 
BRASIL. HumanizaSUS: documento base para gestores e trabalhadores do SUS. 4.ed. rev. Brasília: Ministério da Saúde, 2008a.

Trabalho e redes de saúde: valorização dos trabalhadores da Saúde. 2.ed. Brasília: Ministério da Saúde, 2008b.

CAMPOS, G.W. Saúde Paidéia. São Paulo: Hucitec, 2003.

Um método para análise e co-gestão de coletivos a construção do sujeito, a produção de valor de uso e a democracia em instituições: o Método da Roda. São Paulo: Hucitec, 2000.

A saúde pública e a defesa da vida. São Paulo: Hucitec, 1991.

DESLANDES, S. Humanização e processo comunicacional. In: SEMINÁRIO A HUMANIZAÇÃO DO SUS EM DEBATE, 2008, Vitória. Comunicação... Vitória, 2008.

LOURAU, R. A análise institucional. Petrópolis: Vozes, 1975.

PASCHE, D.F. Princípios do SUS e a humanização das práticas de saúde. In: SEMINÁRIO A HUMANIZAÇÃO DO SUS EM DEBATE, 2008, Vitória. Comunicação... Vitória, 2008.

SADALA, M.L.A. A alteridade: o outro como critério. Rev. Esc. Enferm. USP, v.33, n.4, p.355-7, 1999.

SANTOS-FILHO, S.B. Dando visibilidade à voz dos trabalhadores: possíveis pontos para uma pauta de valorização. In: SANTOS-FILHO, S.B.; BARROS, M.E.B. (Orgs.). Trabalhador da saúde: muito prazer! Protagonismo dos trabalhadores na gestão do trabalho em saúde. ljuí: Ed. Unijuí, 2007. p.261-6.

SANTOS-FILHO, S.B.; BARROS, M.E.B. A base político-metodológica em que se assenta um novo dispositivo de análise e intervenção no trabalho em saúde. In: SANTOSFILHO, S.B.; BARROS, M.E.B. (Orgs.). Trabalhador da saúde: muito prazer! Protagonismo dos trabalhadores na gestão do trabalho em saúde. Ijuí: Ed. Unijuí, 2007. p.123-42. 
Objetiva-se problematizar o lugar ocupado pela Comunidade Ampliada de Pesquisa (CAP) no cotidiano da gestão do cuidado em saúde. A CAP é um momento do Programa de Formação em Saúde e Trabalho (PFST), dispositivo da diretriz "Valorização do Trabalho e do Trabalhador da Saúde" da Política Nacional de Humanização (PNH), e fundamenta-se no diálogo permanente entre os trabalhadores da Saúde e seus distintos saberes. Trata-se de uma construção coletiva sobre os modos de fazer saúde no cotidiano dos serviços. Modos que podem ampliar o diálogo que se desenrola nesse contexto, desequilibrando os arranjos instituídos e construindo condições para a democratização da organização do trabalho, efetivando-se, assim, o protagonismo dos trabalhadores da Saúde.

Palavras-chave: Humanização da assistência. Comunidade ampliada de investigação. Saúde do trabalhador. Gestão em saúde. Educação profissional em saúde pública.

\section{Expanded Research Community (ECR) as a device for co-management: a bet at the collective level}

This paper had the aim of questioning the place occupied by the Expanded Research Community (ECR) in day-to-day healthcare management. The ECR is a point within the Work and Healthcare Training Program (LHTP), which is an instrument for the guideline "Valuing of Work and Healthcare Workers" of the National Humanization Policy (PNH). This is founded on continual dialogue between healthcare workers and their different types of knowledge. This is a collective construction regarding methods for providing healthcare within the day-to-day activities of services. Such methods may expand the dialogue that takes place within this context, to unbalance the established arrangements and build conditions for democratizing the organization of the work, thus making healthcare workers' participation effective.

Keywords: Humanization of assistance. Expanded research community. Occupational health. Healthcare management. Education public health professional.

\section{Comunidad Ampliada de Investigación (CAP) como dispositivo de co-gestión: una apuesta en el plan colectivo}

El presente texto tiene como objeto cuestionar el lugar ocupado por la Comunidad Ampliada (CAP) de Investigación en la gestión cotidiana del cuidado en salud. La CAP es un momento del Programa de Formación en Salud y Trabajo (PFST), dispositivo de la directriz "Valoración del Trabajo y del Trabajador de la Salud" de la Política Nacional de Humanización (PNH) y se fundamenta en el diálogo permanente entre los trabajadores de la Salud y sus distintos saberes. Se trata de una construcción colectiva sobre los modos de hacer salud en el cotidiano de los servicios. Modos que pueden ampliar el diálogo que se desenvuelve en este contexto desequilibrando los arreglos instituidos y construyendo condiciones para la democratización de la organización del trabajo, efectivándose así el protagonismo de los trabajadores de la Salud.

Palabras clave: Humanización de la atención. Comunidad ampliada de investigación. Salud laboral. Gestión en salud. Educación en salud pública professional. 